\section{In Situ PCR: Protocols and Applications}

\section{Gerard J. Nuovo}

Department of Pathology, State University of New York at Stony Brook, Stony Brook, New York

11794
Since the discovery of the structure of DNA in 1953, a great deal of effort has been devoted to detecting specific target sequences. The first commonly used technique, filter hybridization, offered an excellent sensitivity of one copy per 100 cells. Restriction endonuclease digestion in conjunction with electrophoresis and varying stringencies (Southern blot hybridization) allowed for high specificity; however, the prerequisite nucleic acid extraction precluded localization of the target to its specific cell of origin. In many instances, this is critical information. For example, although HIV-1 DNA can be routinely detected from lymph nodes in seropositive, asymptomatic patients, it is very important to note which of the many different cell types that reside in this site are reservoirs of the virus prior to the development of AIDS. Furthermore, simple, although important, data such as the percentage of a given cell type that contains the target of interest cannot be obtained by Southern blot hybridization because of the obligatory destruction of tissue.

About 10 years ago, direct cellular localization of a DNA or RNA target was routinely achieved by in situ hybridization. Over the last 6 years, there have been dramatic improvements in the sensitivity of this method, especially as it relates to nonisotopic probes. ${ }^{(1-3)}$ However, despite these improvements, the relatively high detection threshold of in situ hybridization of $\sim 10$ copies per cell limits its usefulness. ${ }^{(4,5)}$ Although this is not an issue in, for example, productive viral DNA infections where a given cell may contain thousands of copies, common situations such as latent viral infection or point mutations are not detectable by standard in situ hybridization. In addition, mRNA and viral RNAs are often present in copy numbers below the usual in situ hybridization threshold and thus may escape detection. Detection of these low-copy events has become routine over the last 8 years with the widespread use of PCR. Using the hot start maneuver, one copy in a background of $1 \mu \mathrm{g}$ of total cellular DNA can routinely be detected with PCR. ${ }^{(6-8)}$ However, as with filter hybridization, the prerequisite nucleic acid extraction for PCR precludes the determination of which specific cell type contains the target of interest.

During the last 4 years, there has been a dramatic increase in the technology whereby the high sensitivity of PCR is combined with the cell-localizing ability of in situ hybridization. Although still in its relative infancy, many groups have published protocols and data using in situ PCR techniques. ${ }^{(5)}$ This article will discuss some of the basic concepts of in situ PCR, the protocols for in situ detection of PCR-amplified DNA and cDNA, and some of its applications, especially as it relates to HIV-1 and AIDS.

\section{A PROTOCOL FOR IN SITU PCR}

This section will provide an abbreviated protocol for doing in situ PCR, specifically reverse transcriptase (RT) in situ PCR. Detailed information about the various steps is provided in the remainder of this paper.

\section{Preparation of Tissue Sections and Cell Samples}

1. Fix the tissue samples in $10 \%$ buffered formalin, preferably from 8 to 15 $\mathrm{hr}$, and then embed in paraffin. For cell cultures, wash the cells once with PBS directly in the culture plate, add $10 \%$ buffered formalin, let stand overnight, and then scrape the cells off the plate with a rubber policemen. Wash cells in diethylpyrocarbonate (DEPC) water twice, centrifuging at $2000 \mathrm{rpm}$ for 3 min. Resuspend in $5 \mathrm{ml}$ of DEPC water and spot $50 \mu \mathrm{l}$ on a slide.

2. Place several 4- $\mu \mathrm{m}$ paraffin tissue sections or three cell suspensions on silane-coated slides. Silane coating is essential for cell adherence during the procedure. 
3. To remove the paraffin from tissue samples, place slides in fresh xylene for $5 \mathrm{~min}$ and then in $100 \%$ ethanol for $5 \mathrm{~min}$; air-dry.

\section{Protease Digestion}

1. Pepsin, trypsin, or proteinase $\mathrm{K}$ may be used. Pepsin or trysin are preferable because they are less stable than proteinase $\mathrm{K}$ and their activity is inhibited by increasing the $\mathrm{pH}$ during the wash step. Pepsin $(2 \mathrm{mg} / \mathrm{ml})$ is prepared by adding $20 \mathrm{mg}$ of pepsin, $9.5 \mathrm{ml}$ of water, and $0.5 \mathrm{ml}$ of $2 \mathrm{~N} \mathrm{HCl}$.

2. For in situ PCR (with direct incorporation of the reporter molecule during PCR), the proper protease digestion time is highly dependent on the time of fixation in formalin. Refer to Table 2, below, for the proper protease digestion time for a given formalin fixation time.

3. Inactivate the protease by washing the slide in DEPC water for $1 \mathrm{~min}$ and then in $100 \%$ ethanol for $1 \mathrm{~min}$; air-dry. This simple wash step is sufficient to remove/inactivate the protease; heat inactivation is not required.

\section{DNase Digestion (For RT In Situ PCR)}

1. It is important to digest two of the three tissue sections/cell suspensions with DNase. The positive control is the section that is not treated with DNase. An intense signal in at least $50 \%$ of cells demonstrates that protease digestion time is optimal; the signal represents DNA repair, genomic amplification, and mispriming. The negative control is the cell suspension/tissue section that is DNase digested and not treated with RT. The absence of signal demonstrates that the DNase digestion has rendered the native DNA template unavailable for DNA synthesis. The test is the section digested by DNase digestion that is then treated with RT.

2. To two of the three sections, add

$1 \mu \mathrm{l}$ of $10 \times$ buffer*

$1 \mu 1$ of RNase-free DNase (Boehringer Mannheim, $10 \mathrm{U} / \mu \mathrm{l}$ )

$8 \mu$ l of DEPC water

Cover the solution with the inside of the autoclaved plastic from the polypropylene bags to prevent drying. Place the slides in a humidity chamber at $37^{\circ} \mathrm{C}$.

3. After overnight digestion, remove the coverslip, wash for $1 \mathrm{~min}$ in DEPC water and $100 \%$ ethanol, and air-dry. *The $10 \times$ buffer is made by adding 35 $\mu \mathrm{l}$ of $3 \mathrm{M}$ sodium acetate, $5 \mu \mathrm{l}$ of $1 \mathrm{M} \mathrm{MgSO}_{4}$, and $60 \mu \mathrm{l}$ of DEPC water.

\section{RT step}

1. Place the following solution on 1 of the 2 sections treated with DNase:

$2 \mu \mathrm{l}$ of $\mathrm{MgCl}_{2}$ (25 mM stock)*

$1 \mu l$ of th RT buffer

$1 \mu \mathrm{l}$ each of dATP, dCTP, dGTP, dTTP (stock of each nucleotide at 10 $\mathrm{mM}$ )

$1.5 \mu \mathrm{l}$ of DEPC water

$0.5 \mu \mathrm{l}$ of $3^{\prime}$ primer ( $20 \mu \mathrm{M}$ stock solution)

$0.5 \mu$ l of RNase inhibitor

$0.5 \mu$ of RT

*These reagents are from the RT-PCR kit (Perkin-Elmer Corporation).

2. To prevent drying, anchor coverslip with one small drop of nail polish, place the slide in an aluminum "boat" on the block of a thermal cycler, and incubate at $42^{\circ} \mathrm{C}$ for $30 \mathrm{~min}$; cover with sterile mineral oil.

3 . Remove the coverslip; then remove oil with a 5-min wash in xylene, followed by a 5 -min wash in $100 \%$ ethanol. 


\section{PCR Step}

1. For each slide, prepare $25 \mu$ l of solution:

$2.5 \mu \mathrm{l}$ of PCR buffer*

$4.5 \mu \mathrm{l}$ of $\mathrm{MgCl}_{2}$ (25 mM stock solution)

$4.0 \mu \mathrm{l}$ of dNTP solution ( $200 \mu \mathrm{M}$ final concentration of each nucleotide)

$1.0 \mu \mathrm{l}$ of $2 \%$ bovine serum albumin (BSA)

$0.4 \mu \mathrm{l}$ of digoxigenin dUTP solution (1 mM stock solution)

$1 \mu \mathrm{l}$ each of primer 1 and primer $2(20 \mu \mathrm{M})$

$11 \mu \mathrm{l}$ of water

$0.5 \mu$ l of Taq polymerase

2. Add this solution to the slide and cover with one large coverslip; anchor with two small drops of nail polish.

3. Ramp to $80^{\circ} \mathrm{C}$, add preheated mineral oil, abort file, go to $94^{\circ} \mathrm{C}$ for 3 min, cycle at $55^{\circ} \mathrm{C}$ for $2 \mathrm{~min}, 94^{\circ} \mathrm{C}$ for $1 \mathrm{~min}$ for 15 cycles (in situ PCR) or 35 cycles (PCR in situ hybridization).

4. Remove the coverslip and polish, wash for $5 \mathrm{~min}$ in xylene, $5 \mathrm{~min}$ in ethanol, and air-dry.

*The solutions are from the GeneAmp kit (Perkin-Elmer).

\section{Detection Step}

1. Wash the slides for $3 \mathrm{~min}$ in a $1 \times \mathrm{SSC}$ solution at $52^{\circ} \mathrm{C}$ that contains $0.2 \%$ BSA.

2. Remove excess wash solution. Add to each slide $100 \mu \mathrm{l}$ of a $0.1 \mathrm{M}$ Tris (pH 7.5) and $0.1 \mathrm{M} \mathrm{NaCl}$ solution with the anti-digoxigenin antibody (1:200 dilution) (Boehringer Mannheim). Incubate for $30 \mathrm{~min}$ at $37^{\circ} \mathrm{C}$.

3. Wash the slides for $1 \mathrm{~min}$ in the detection solution $(0.1 \mathrm{M}$ Tris at $\mathrm{pH} 9.5$ and $0.1 \mathrm{M} \mathrm{NaCl}$ ). Then, incubate the slides in the detection solution, to which is added NBT/BCIP chromagen (Boehringer Mannheim). Incubate at $37^{\circ} \mathrm{C}$ for 5-15 min. Check the slides under a microscope and stop the reaction when the signal is strong.

4. Wash in water for $1 \mathrm{~min}$, counterstain with nuclear fast red for $5 \mathrm{~min}$, wash in water for $1 \mathrm{~min}$, and then wash in $100 \%$ ethanol and xylene $(1 \mathrm{~min}$ each). Cover with a coverslip using Permount. View under a microscope.

\section{Interpretation Step}

1. If the positive control has $>50 \%$ positive cells and the negative control shows no positive cells, then the RT/DNased section should show target-specific cDNA amplification.

2. If the negative control shows positive cells, then increase protease digestion time.

3. If both the negative and positive controls do not show positive cells, then check the tissue morphology. If it is poorly preserved, decrease the protease digestion time. If it is well preserved, increase the protease digestion time.

\section{THE BASICS OF IN SITU PCR}

\section{Tissue Preparation}

The choice of fixative is essential for in situ PCR. Certain fixatives function by denaturing proteins and, in this way, render degradative enzymes inoperative. Common examples include acetone and ethanol. The most commonly used fixative in anatomic pathology is $10 \%$ buffered formalin, which crosslinks proteins and nucleic acids and thus has a mode of action very different 
from acetone and ethanol. For some tissues, such as bone marrow and lymph node biopsies, formalin with picric acid (e.g., Bouin's solution) or with a heavy metal such as mercury (e.g., Zenker's solution) is sometimes employed because these solutions tend to give better nuclear detail with microscopic sections (which is important in the analysis of lymphomas). Finally, immunohistochemistry at times requires frozen, unfixed tissues for preservation of the antigenic determinant, although many antigens are well preserved after formalin fixation and paraffin embedding.

Successful in situ hybridization and PCR can be done with unfixed, frozen tissue or after fixation in acetone, ethanol, or buffered formalin. Fixatives that include a heavy metal or picric acid do not allow for PCR because of the rapid and extensive degradation of the DNA. ${ }^{(9)}$ Tissues fixed for $>8 \mathrm{hr}$ in solutions that contain either a heavy metal or picric acid do not allow for a signal with in situ hybridization, although shorter-term fixation can yield intense signals. ${ }^{(10)}$

We performed a study of the utility of different fixatives with in situ PCR. The basis of these experiments was to use a cell line with a known target and determine which fixatives allowed for a detection rate of $100 \% .{ }^{(11)}$ The data from these experiments are presented in Table 1 . Note that only buffered formalin fixation followed by protease digestion allowed for a $100 \%$ detection rate of the $b c l-2$ target with in situ PCR. It was surprising that acetone or ethanol fixation did not allow for $100 \%$ detection rates under the conditions employed in the study. Possible explanations are that these fixations did not permit adequate amplification in the nuclei of most cells or that amplification occurred but that the PCR product migrated out of the cell into the amplifying solution. To test these hypotheses, the DNA from the cell and from the amplifying solutions was retrieved after in situ PCR, extracted, and then tested by Southern blot hybridization for the 502-bp target from the $b c l-2$ gene. These experiments demonstrated that the amplifying solution of the cells fixed in acetone or ethanol but not formalin contained the $b c l-2$ PCR product. This leads to the important topic of the migration barrier with in situ PCR. It was concluded that ethanol and acetone fixation do allow for intranuclear DNA synthesis but that, in many cells, the PCR product migrates out of the cell. However, formalin fixation appears to create a migration barrier that, under certain specified conditions, severely limits the movement of the

TABLE 1 The Effect of Fixation Chemistry and Duration on the Detection of Amplified $b c l-2$ DNA in Peripheral Blood Mononuclear Cells

\begin{tabular}{lcccc}
\hline & \multicolumn{4}{c}{ No protease digestion (\% positive cells) } \\
Fixation & \multicolumn{5}{c}{ (fixative) } \\
\cline { 2 - 5 } time & formalin & acetone & $95 \%$ ETOH & Bouin's \\
\hline $5 \mathrm{~min}$ & 5 & 2 & 14 & 0 \\
$15 \mathrm{hr}$ & 0 & 15 & 31 & 0 \\
$39 \mathrm{hr}$ & N.D. & 0 & 9 & N.D. \\
& & With protease digestion (\% positive cells) & \\
Fixation time/ & & acetone & $95 \%$ ETOH & Bouin's \\
protease condition & formalin & 0 & 0 & 0 \\
\hline $5 \mathrm{~min} / 2 \mathrm{mg} / \mathrm{ml}, 12 \mathrm{~min}$ & 0 & 0 & 0 & - \\
$5 \mathrm{~min} / 20 \mu \mathrm{g} / \mathrm{ml}, 1 \mathrm{~min}$ & 1 & 0 & 0 & - \\
$5 \mathrm{~min} / 20 \mu \mathrm{g} / \mathrm{ml}, 2 \mathrm{~min}$ & 35 & 0 & 0 & - \\
$5 \mathrm{~min} / 20 \mu \mathrm{g} / \mathrm{ml}, 5 \mathrm{~min}$ & 0 & 0 & 0 & 0 \\
$15 \mathrm{hr} / 2 \mathrm{mg} / \mathrm{ml}, 12 \mathrm{~min}$ & 100 & &
\end{tabular}

(N.D.) Not done. 
PCR product from its site of synthesis in the cell. It is reasonable to assume that this relates to the protein-DNA latticework that occurs secondarily to the cross-links created after formalin fixation.

Recently, there has been a concerted effort to find alternatives to formalin in the pathology laboratory because of the possible carcinogenic effects of this fixative. Fixatives that do not contain formalin include Histochoice and Streck's solution. We and others have found that these fixatives do permit in situ PCR with cell suspensions and tissue sections without the need for a protease digestion step. However, in our experience, these fixatives do not allow for the precise subcellular localization of the cross-linking fixatives or for a $100 \%$ detection rate. ${ }^{(5)}$

\section{Protease Digestion}

A review of the data in Table 1 will underscore that $100 \%$ detection of the target was achieved only when prolonged formalin fixation was followed by protease digestion. Our attempts to obtain $100 \%$ detection rates with very brief (5-min) fixation times with buffered formalin and no or minimal protease digestion were not successful. We expanded this study to tissues fixed in buffered formalin for times that ranged from $4 \mathrm{hr}$ to 1 week. ${ }^{(12)}$ These data are presented in Table 2 . Note that the signal evident with in situ PCR for formalin-fixed tissues was strongly dependent on the length of times of formalin fixation and digestion in the protease. It is very important to stress that these data apply to direct incorporation of the reporter molecule into the PCR product, which is called in situ PCR in this paper. This is to be differentiated from PCR in situ hybridization, where the PCR product is detected by a labeled internal oligoprobe after a hybridization step. The optimal protease digestion time does not vary much with PCR in situ hybridization, where it is from 20 to $30 \mathrm{~min}$ for tissues fixed for $4 \mathrm{hr}$ to several days. ${ }^{(5)}$

Several proteases have been tested extensively for in situ hybridization, including proteinase $\mathrm{K}$, pepsin, trypsin, trypsinogen, and Pronase. In our experience, all of these proteases allow for successful in situ amplification of DNA and cDNA. We prefer trypsin or pepsin at a low $\mathrm{pH}$ because a simple change of $\mathrm{pH}$ to 7 is enough to reduce the activity of the protease. Also, proteinase $\mathrm{K}$ tends to cause overdigestion more commonly. This can be recognized as the absence of signal and concomitant poor morphology (Fig. 1).

For those doing in situ PCR or RT in situ PCR, a very important point is

TABLE 2 The Effect of Protease Digestion Time on the Primer-independent Signal During In Situ PCR as a Function of the Time of Fixation in 10\% Buffered Formalin

\begin{tabular}{|c|c|c|c|c|c|c|c|c|c|}
\hline \multirow{2}{*}{$\begin{array}{l}\text { Fixation } \\
\text { time }\end{array}$} & \multicolumn{9}{|c|}{ Protease $^{a}$ digestion time (min) } \\
\hline & 0 & 5 & 10 & 15 & 30 & 45 & 60 & 75 & 90 \\
\hline $4 \mathrm{hr}$ & 0 & $1+$ & $3+$ & $2+$ & overdigested $^{\mathrm{b}}$ & & & & \\
\hline $6 \mathrm{hr}$ & 0 & 0 & $1+$ & $3+$ & $2+$ & overdigested $^{\mathrm{b}}$ & & & \\
\hline $8 \mathrm{hr}$ & 0 & 0 & 0 & 0 & $1+$ & $3+$ & - & - & - \\
\hline $15 \mathrm{hr}$ & 0 & 0 & 0 & 0 & 0 & $1+$ & $1+$ & $2+$ & $3+$ \\
\hline $48 \mathrm{hr}$ & 0 & 0 & 0 & 0 & 0 & 0 & $1+$ & $2+$ & $3+$ \\
\hline 1 week & 0 & 0 & 0 & 0 & 0 & 0 & $1+$ & $1+$ & $2-3+^{c}$ \\
\hline
\end{tabular}

The signal was scored as follows: $0,1+(<25 \%$ of cells positive), $2+(25-50 \%$ cells positive), and $3+(>50 \%$ of cells positive). Signal measurements were made without knowledge of the reaction conditions.

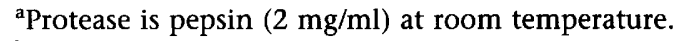

${ }^{b}$ Overdigested refers to loss of tissue morphology with a concomitant loss of the in situ PCR signal.

'The $2+$ signal was with pepsin; the $3+$ signal with proteinase $\mathrm{K}$ digestion $(1 \mathrm{mg} / \mathrm{ml})$. 

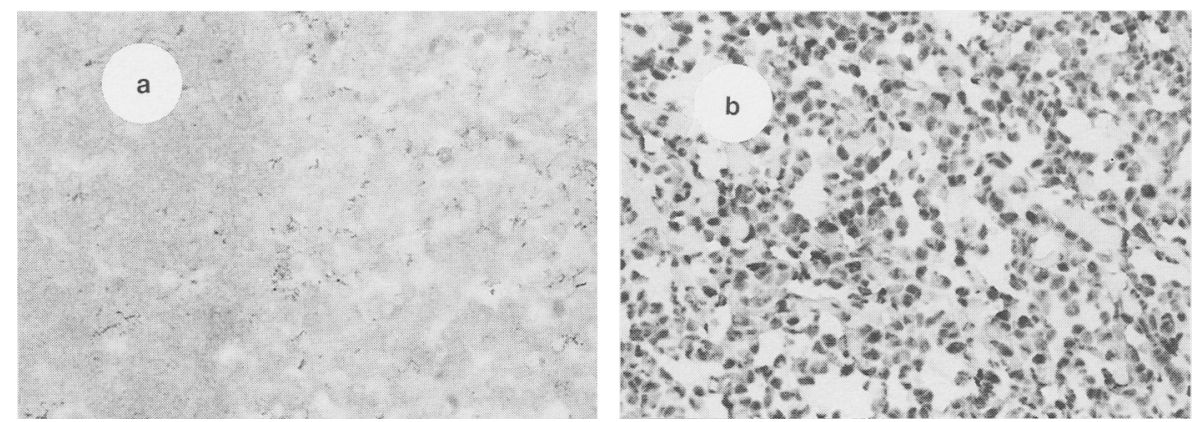

FIGURE 1 Over protease digestion of tissue. This tonsillar tissue was fixed in buffered formalin for $4 \mathrm{hr}$. No signal is evident with in situ PCR using $b c l-2$ primers if the protease digestion time (pepsin $2 \mathrm{mg} / \mathrm{ml}$ ) was for $30 \mathrm{~min}(a)$; note the poor morphologic detail. If the digestion time was decreased to $10 \mathrm{~min}$, an intense signal and good morphologic detail are evident $(b)$.

evident from Table 2. The optimal protease time is dependent on the time of formalin fixation and can be defined by a $3+$ signal (an intense signal in $>50 \%$ of cells). If the signal is not $3+$ for a given protease digestion time, then it can be assumed that the time is suboptimal and that increasing the digestion times should be tried until a $3+$ signal is obtained. Inadequate protease digestion is probably the most common cause of unsuccessful in situ PCR. This important principle is illustrated in Figure 2.

\section{Amplifying Solution}

There are some important differences in the composition of the amplifying solution when comparing in situ PCR to solution-phase PCR. The optimal $\mathrm{MgCl}_{2}$ concentration for solution phase PCR is usually from 1 to $4 \mathrm{mM}$, with $1.5 \mathrm{~mm}$ being a typical starting point. We varied the $\mathrm{MgCl}_{2}$ concentration from 0 to $9 \mathrm{~mm}$ for a variety of primers and targets. In each case, an optimal signal for in situ PCR was obtained with $4.5 \mathrm{~mm} \mathrm{MgCl}_{2}{ }^{(5,11)}$ (Fig. 3). This relatively high and constant concentration for magnesium probably reflects its partial sequestration on the glass slide and cellular proteins.

The composition of the buffer (PCR buffer II, GeneAmp kit, Perkin-Elmer Corporation, Norwalk, CT) and the concentration of the nucleotides $(200 \mu \mathrm{M})$ and primers $(1 \mu \mathrm{M})$ with in situ PCR are equivalent to those used for solutionphase PCR. The other major difference in the composition of the amplifying solution with regard to in situ PCR is the concentration of the DNA (Taq) polymerase (Perkin-Elmer). A usual concentration for the Taq polymerase with solution-phase PCR is $1.5 \mathrm{U} / 50 \mu \mathrm{l}$. In our experience, this concentration
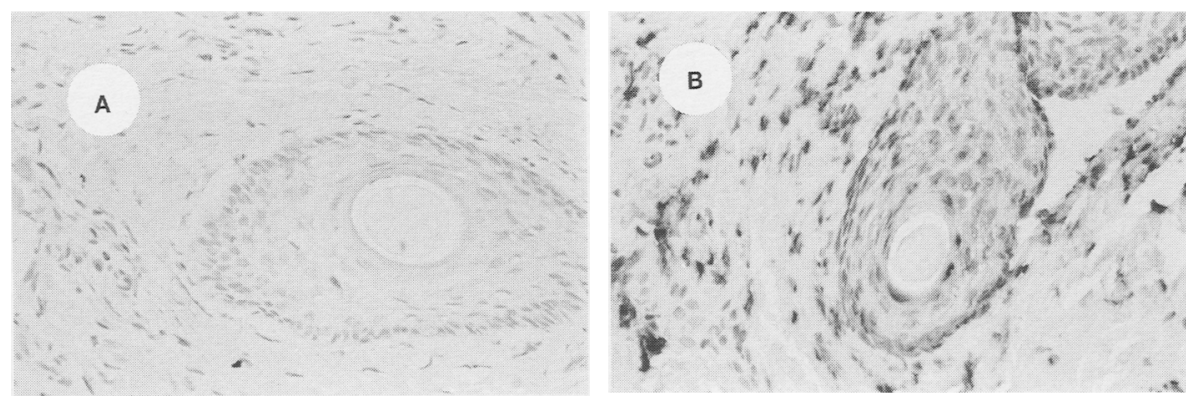

FIGURE 2 Relationship of protease digestion and formalin fixation times for successful in situ PCR. This skin biopsy was fixed in buffered formalin for $8 \mathrm{hr}$. No signal is evident with in situ PCR if the pepsin digestion time was for $15 \mathrm{~min}(A)$. An intense signal is evident if the digestion time is increased to $45 \mathrm{~min}(B)$. 

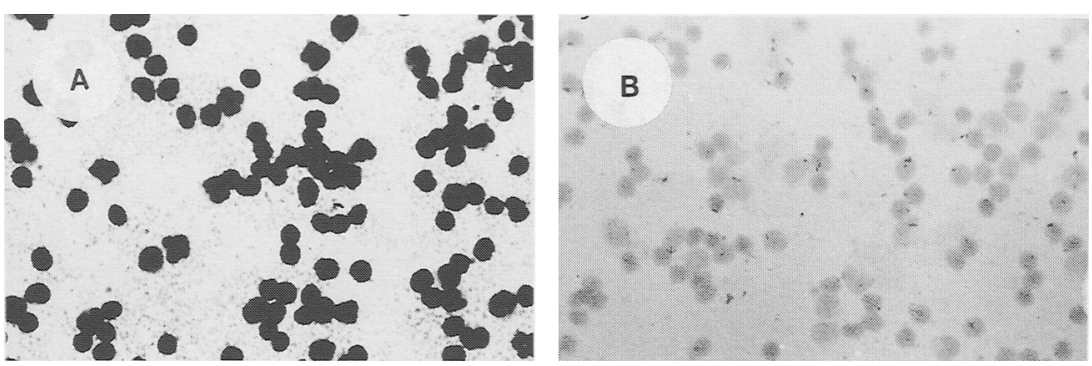

FIGURE 3 Importance of $\mathrm{MgCl}_{2}$ concentration for successful in situ PCR. At a $\mathrm{MgCl}_{2}$ concentration of $4.5 \mathrm{~mm}$, all peripheral blood mononuclear cells fixed for $15 \mathrm{hr}$ in buffered formalin and digested have an intense signal using in situ PCR and $b c l-2$ primers $(A)$. No signal is evident if $\mathrm{MgCl}_{2}$ is omitted $(B)$. Similar poor results were obtained with magnesium concentrations of 1.5 , 6.0 , and $9.0 \mathrm{~mm}$.

will not produce an intense signal with in situ PCR. Rather, $15 \mathrm{U} / 50 \mu \mathrm{l}$ was initially required. It is feasible that this higher concentration reflects partial adsorption of the polymerase onto the glass slide and plastic coverslip. To test this hypothesis, $1.5 \mu \mathrm{l}$ of $2 \% \mathrm{BSA}$ was added to the amplifying solution; BSA is used commonly in immunohistochemistry to inhibit nonspecific binding of proteins to the slide or tissue section. The addition of BSA allowed for an intense hybridization signal after in situ PCR with a Taq concentration of 1.5 $\mathrm{U} / 50 \mu \mathrm{l} .{ }^{(5,11)}$

\section{The Nonspecific Pathways During In Situ PCR}

It has been long recognized that primer-dependent, nonspecific DNA synthesis can be operative during solution-phase PCR. Mispriming and primer oligomerization can lead to nonspecific bands that can cause false-positive results with solution-phase PCR. Importantly, it is now recognized that these nonspecific pathways can profoundly affect the detection threshold of solution-phase PCR. It is relatively simple to inhibit these nonspecific pathways without compromising target-specific primer annealing. This can be done by taking advantage of the lower melting temperatures of the nonspecific pathways resulting from the less than $100 \%$ homology between the primer and the nontarget DNA (mispriming) or another primer (primer oligomerization). By withholding the $T a q$ polymerase until $55^{\circ} \mathrm{C}$ is reached, one can strongly inhibit these two nonspecific pathways without inhibiting primer-target annealing. This procedure is commonly referred to as "hot start PCR." Several groups have shown that the detection threshold of solution-phase PCR in the setting of $1 \mu \mathrm{g}$ of total cellular DNA is several thousand copies per amplifying solution. Routine amplification of 1-10 copies in this setting is achieved with hot start PCR. Thus, the hot start maneuver, which can be achieved with AmpliWax beads (Perkin-Elmer), increases the sensitivity of solution-phase PCR by at least two orders of magnitude. ${ }^{(6-8)}$

We examined the contribution of the nonspecific DNA synthesis pathways during in situ PCR ${ }^{(5,12)}$ A strong primer-independent signal was present during in situ PCR. This initial observation was made with paraffin-embedded, formalin-fixed tissue. The two major procedural steps with paraffin embedding are washing the tissues in graded ethanol and xylene after fixation and embedding at $65^{\circ} \mathrm{C}$ for $4 \mathrm{hr}$ in the paraffin wax. To determine which of these steps was related to the primer-independent signal, we took frozen, fixed tissues and treated them to either graded ethanol and xylene or $65^{\circ} \mathrm{C}$ for $4 \mathrm{hr}$. An intense primer-independent signal was evident only in the tissue that was heated at $65^{\circ} \mathrm{C} .^{(5,12)}$ Similarly, no primer-independent signal was evident in 
cytospin preparations (these are cells placed on a glass slide with a centrifuge) unless the cells were heated to $65^{\circ} \mathrm{C}$ after fixation and prior to in situ PCR. ${ }^{(5,12)}$

To determine whether the primer-independent signal required an intact DNA template, the tissue sections were treated overnight in a solution tht contained RNase-free DNase (10 units/section). The primer-independent signal could be eliminated under these conditions (Fig. 4), but this loss of signal was also highly related to the times of fixation and protease digestion (Table $3) .{ }^{(5,12)}$ Note that for a given fixation time the protease time that resulted in an optimal signal yielded no signal after the DNase predigestion. However, when less than optimal protease times were used, there was at times an enhanced signal for the DNase-digested section when compared with the non-DNase-digested serial section present on the same glass slide.

The primer-independent signal could represent repair of single-stranded gaps or nicks. Incorporation of a dideoxynucleotide in regions of DNA gaps could render such areas unavailable to digoxygenin incorporation during the PCR part of the procedure. To test this hypothesis, we pretreated the sections after protease digestion in a solution that contained dideoxy-TTP (in a ratio of 20:1 with respect to dTTP as well as dATP, dCTP, and dGTP) and Taq polymerase. After this pretreatment and removal of the dideoxy-TTP by washing, in situ PCR was performed in the absence of any primers. The results are compiled in Table 4 . Two similarities with the data for the DNase pretreatment are evident: (1) At the protease time optimal for the primer-independent signal, the dideoxy pretreatment eliminated the nonspecific signal; (2) at suboptimal protease times (a signal less than $3+$ with no pretreatment step), the dideoxy pretreatment at times enhanced the signal relative to the serial section on the same glass slide that was not pretreated with dideoxyTTP. Note that unlike the DNase experiments, a signal reemerges after dideoxy pretreatment with supraoptimal protease digestion times (digestion times greater than that required to produce a $3+$ signal with no pretreatment step). An alternative explanation for the elimination of the primer-independent signal with dideoxy pretreatment under the conditions defined above is that the polymerase activity of the Taq polymerase during the pretreatment step "filled" in the putative gaps and that this, rather than dideoxy termination, was responsible for the loss of the signal during the subsequent in situ PCR. To test this hypothesis, direct comparisons on the same glass slide were done of the pretreatment step with and without the $1000 \mu \mathrm{M}$ of the dideoxyTTP under the optimal protease digestion conditions. The signal that was completely blocked with dideoxy pretreatment during in situ PCR was $3+$ if the dideoxy-TTP was omitted from the pretreatment solution and replaced
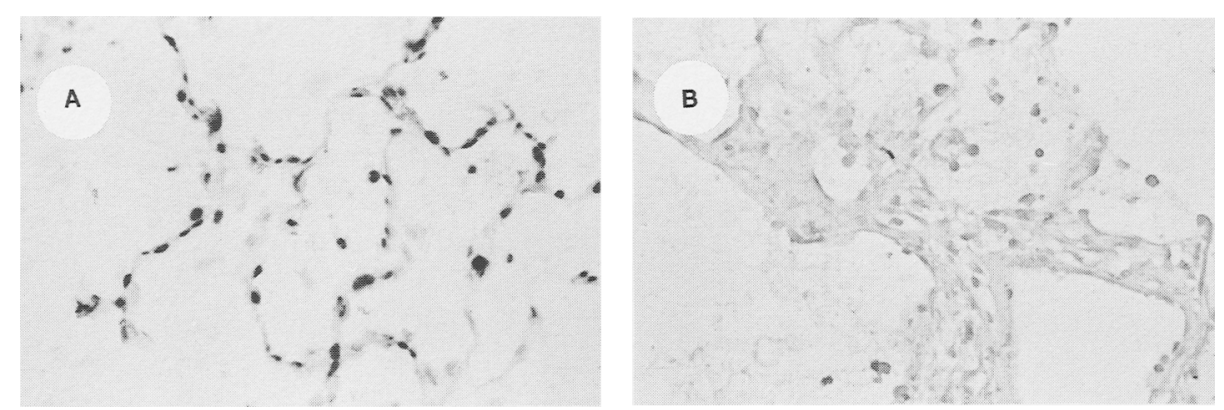

FICURE 4 Primer-independent DNA synthesis during in situ PCR. An intense signal is evident in this fixed, paraffin embedded lung biopsy if in situ PCR is done without primers $(A)$. The signal was eliminated by digesting the tissue in DNase overnight prior to in situ PCR $(B)$. The signal was also lost if the tissue was frozen, sectioned, and then fixed (see Ref. 5 or 12); the primerindependent signal requires heating of the tissue, which is obligatory during paraffin embedding. 
TABLE 3 The Effect of Protease Digestion Time on the Primer-independent Signal During In Situ PCR with and without Overnight Digestion in RNase-free DNase

\begin{tabular}{|c|c|c|c|c|c|}
\hline \multirow[b]{2}{*}{ Fixation time } & \multicolumn{5}{|c|}{ Protease digestion time (min) } \\
\hline & 15 & 30 & 45 & 60 & 90 \\
\hline \multicolumn{6}{|l|}{$8 \mathrm{hr}$} \\
\hline no DNase digestion & 0 & $1+$ & $3+$ & $2+$ & - \\
\hline DNase digestion & $2+$ & 0 & 0 & 0 & - \\
\hline \multicolumn{6}{|l|}{$15 \mathrm{hr}$} \\
\hline no DNase digestion & 0 & 0 & $1+$ & $1+$ & $3+$ \\
\hline DNase digestion & $2+$ & $2+$ & $1+$ & 0 & 0 \\
\hline
\end{tabular}

with $150 \mu \mathrm{M}$ dTTP, demonstrating that dideoxy nucleotide in the pretreatment step was crucial for the subsequent elimination of the primer-independent signal during in situ PCR.

In summary, it was concluded that the primer-independent signal evident during in situ PCR represented Taq-mediated repair of single-stranded gaps in the genomic DNA induced by rapid heating during the paraffin-embedding process. This DNA repair could be blocked by pretreatment in DNase or with a dideoxynucleotide, although successful blockage was highly dependent on the times of formalin fixation and protease digestion.

We then studied whether the primer-independent pathway was operative during solution-phase PCR. Total cellular DNA was extracted from fresh peripheral blood mononuclear cells isolated from a Ficoll gradient and treated with $10 \%$ buffered formalin for $3 \mathrm{hr}$ either at room temperature or at $68^{\circ} \mathrm{C}$. The effect of BSA was also tested by adding $2 \mathrm{ng} / \mu \mathrm{l}$ of the protein to a sample of the DNA treated with formalin and heat. The DNA was then ethanol precipitated and subjected to PCR with direct incorporation of ${ }^{32} \mathrm{P}$-labeled dCTP. As is evident from Figure 5, a primer-independent signal required that the DNA be fixed in formalin at $68^{\circ} \mathrm{C}$ in the presence of BSA. ${ }^{(5,12)}$ Similarly, the DNA was extracted from the frozen, fixed, or paraffin-embedded formalinfixed lymphoid tissues, ethanol precipitated, and also subjected to solutionphase PCR with ${ }^{32}$ P-labeled dCTP incorporation. A primer-independent signal was evident in the DNA extracted from the paraffin-embedded, fixed tissue but not the frozen, fixed tissue. ${ }^{(5,12)}$ To determine whether DNA-protein cross-linking by formalin was required for the primer-independent signal

TABLE 4 The Effect of Protease Digestion Time on the Primer-independent Signal During In Situ PCR with and without Pretreatment in Dideoxy-TTP

\begin{tabular}{llccc}
\hline & \multicolumn{4}{c}{ Protease digestion time (min) } \\
\cline { 2 - 5 } Fixation time & 5 & 10 & 15 & 20 \\
\hline $6 \mathrm{hr}$ & $0+$ & $1+$ & $3+$ & $2+$ \\
no dideoxy treatment & $2+$ & $1+$ & 0 & $3+$ \\
dideoxy pretreatment & & Protease digestion time (min) & \\
\cline { 2 - 4 } & 15 & 30 & 45 & 60 \\
\hline $8 \mathrm{hr}$ & & & $3+$ & $2+$ \\
no dideoxy treatment & 0 & $1+$ & 0 & $2+$ \\
dideoxy pretreatment & $2+^{\mathrm{a}}$ & $1+$ & $3+$ \\
\hline
\end{tabular}

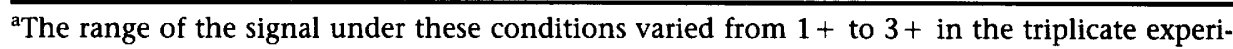
ments, whereas each result was 0 for the tissue section not pretreated with the dideoxy nucleotide. 


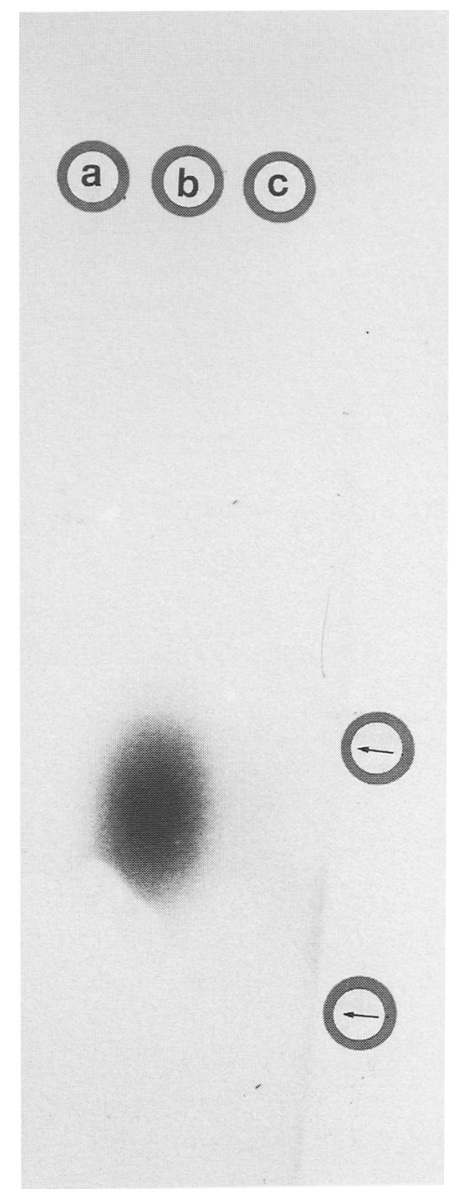

FIGURE 5 Primer-independent DNA synthesis during solution-phase PCR. The DNA was extracted from peripheral blood mononuclear cells and then fixed for $3 \mathrm{hr}$ in formalin at room temperature (lane $a$ ), in formalin and BSA at $68^{\circ} \mathrm{C}$ (lane $b$ ), or in formalin at $68^{\circ} \mathrm{C}$ for $3 \mathrm{hr}$, precipitated, and subjected to PCR with direct incorporation using ${ }^{32}$ P-labeled dCTP without primers. Note that primer-independent DNA synthesis is evident only after formalin fixation and heat in the presence of BSA. The arrows marks $700 \mathrm{bp}$ and $300 \mathrm{bp}$ as detected on the ethidium gel using a 100-bp ladder.

during solution-phase PCR, we used highly purified salmon sperm DNA. The salmon sperm DNA $(2.5 \mu \mathrm{g})$ was subjected to fixation for $4 \mathrm{hr}$ in either $95 \%$ ethanol, acetone, or $10 \%$ buffered formalin; the addition of $2.5 \mu \mathrm{g}$ of BSA with each fixative was also tested. The purified DNA, which according to the manufacturer is $\sim 800 \mathrm{bp}$ in size and was heated at $121^{\circ} \mathrm{C}$ during the processing, was subjected to solution-phase PCR in the absence of primers. A primerindependent signal at the expected size of $800 \mathrm{bp}$ was only evident for the DNA fixed in formalin in the presence of BSA. The signal was lost from the DNA fixed in formalin with BSA after postdigestion in $1 \mathrm{mg} / \mathrm{ml}$ of proteinase $\mathrm{K}$ for $3 \mathrm{hr}$ at $55^{\circ} \mathrm{C}$; the protease was degraded prior to PCR by heating at $95^{\circ} \mathrm{C}$ for $10 \mathrm{~min} .{ }^{(12)}$

In summary, it was determined that the primer-independent signal could be induced in solution-phase PCR. This required DNA that was heated in the presence of a protein and a cross linking type fixative. Intact protein-DNA cross-links were required, as evidenced by the loss of the primer-independent signal if solution-phase PCR was preceded by protease digestion. This is the reason that the primer-independent signal is rarely evident during solutionphase PCR, because protease digestion is a routine step in the extraction of DNA from tissues or cell suspensions. 
We then attempted to determine the relative contribution of the nonspecific primer-dependent pathways (mispriming and primer oligomerization) to the signal evident with in situ PCR. The basis of these analyses included skin and tonsil tissues and primers that amplify regions of the measles virus, cytomegalovirus, and Epstein-Barr virus. The tissues were not infected by these viruses based on the lack of the characteristic histologic changes. Thus, any signal generated during in situ PCR with these primers would be nonspecific. Demonstration that the nonspecific signal was completely eliminated with overnight DNase digestion, presupposing optimal protease pretreatment, allowed for the study of the contribution of primer oligomerization, as the DNase digestion should eliminate the possibility of mispriming. The use of any of the viral primer pairs listed above in tissues digested by DNase under optimal protease conditions did not allow for a signal in the cells. ${ }^{(12)}$ The experiments were done under "cold start" conditions to enhance the production of the primer dimers. Solution-phase PCR of the amplifying solution confirmed that the reporter molecule was robustly incorporated by the process of primer oligomerization. It is concluded that a "migration barrier" may inhibit entry into the cell of the relatively small double-stranded primer dimers but not of the individual single-stranded primers. Primer oligomerization also appears to be limited severely within the confines of the DNA-protein meshwork present in the formalin-fixed cell.

To test the role of mispriming during in siutu PCR, it was necessary to eliminate the nonspecific primer-independent signal without compromising the integrity of the DNA so that viral primers could anneal with the nontarget human DNA. This could be achieved either by using frozen, fixed tissue or paraffin-embedded tissue that was pretreated with optimal protease digestion time and dideoxy-TTP blockage. Both series of experiments were performed with human papillomavirus (HPV) primers and HPV DNA-negative tissues and yielded equivalent results. Specifically, if the hot start PCR reaction conditions were employed where the Taq polymerase was not added until the block of the thermal cycler reached $55^{\circ} \mathrm{C}$, then no signal was evident. ${ }^{(12)}$ However, when the Taq polymerase was added at room temperature at the onset of PCR, a $2+$ to $3+$ signal was evident in the skin and tonsil tissues (Fig. 6).

In summary, primer oligomerization does not appear to induce a signal during in situ PCR even when it is occurring robustly in the amplifying solution. However, mispriming can induce a signal during in situ PCR, but this can be blocked by using the hot start maneuver, i.e., adding the Taq
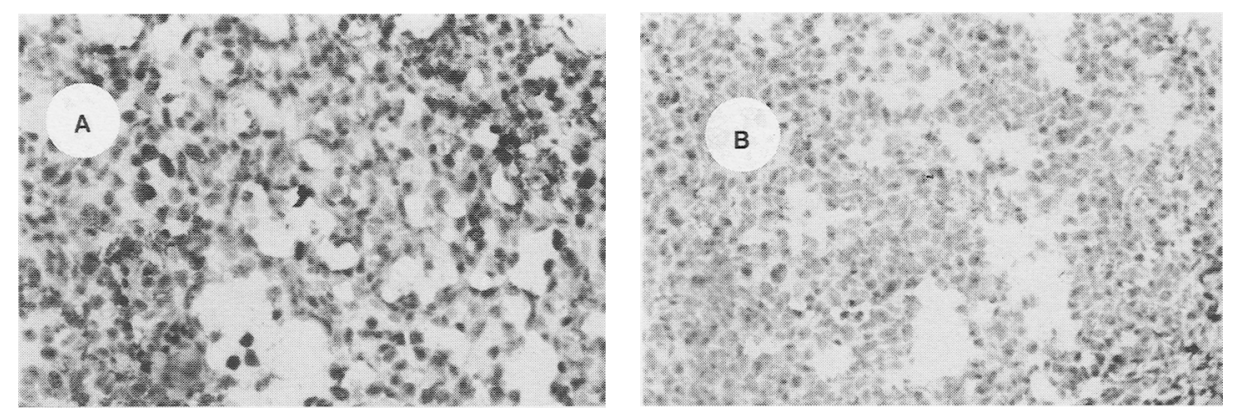

FICURE 6 Mispriming during in situ PCR. Effect of mispriming on the signal during in situ PCR. The tissue is from the tonsil, which was frozen, sectioned, and then fixed in formalin without heating. In situ PCR was done with HPV-specific primers; any signal should represent mispriming because HPV does not infect lymphoid tissue. A signal was noted if the Taq polymerase was added at room temperature $(A)$. The signal was lost if the Taq polymerase was not added until the reaction temperature reached $55^{\circ} \mathrm{C}(B)$. 
polyermase to the amplifying solution after the thermal cycler block reaches $55^{\circ} \mathrm{C}$.

\section{SPECIFIC PROTOCOLS}

In this section the protocols used for the in situ detection of PCR-amplified DNA and cDNA in intact cells are described.

\section{PCR In Situ Hybridization}

PCR in situ hybridization is best used to detect DNA in paraffin-embedded tissue sections. The DNA repair pathway invariably present in these tissues precludes target-specific incorporation of the reporter nucleotide. Although one could achieve this result after pretreatment with a dideoxynucleotide, this is not recommended because the very narrow "window" of optimal protease time leads to a high possibility of a false-positive result (see Table 3). Our PCR in situ hybridization protocol is listed in Figure 7. It is recommended that at least three tissue sections or cytospins be placed on a glass slide, which allows the test to be performed with the negative control (e.g., no Taq polymerase) or with the positive control (e.g., a target present in every cell) on the same glass slide. It is also important to stress the need for the hot start maneuver to detect reliably one target copy per cell using a single primer pair. ${ }^{(5,8)}$

\section{In Situ PCR}

With in situ PCR, the major procedural differences are the inclusion of a reporter molecule in the amplification step and the omission of the in situ

1. Place 3 paraffin embedded tissue sections on silane slides, remove paraffin, protease digest for 20-30 min.

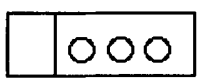

2. Place PCR reagent over 1 section; use others for - and + control. Place slide on thermal cycler.

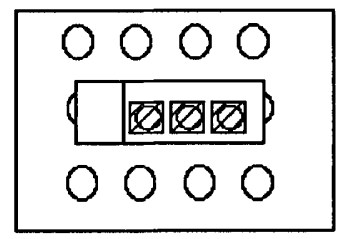

3. Do PCR for 30 cycles, wash in xylene and ETOH, then do in situ hybridization with internal oligoprobe.

\section{国因图}

4. Wash in $1 \mathrm{XSSC}$ with $0.2 \% \mathrm{BSA}$ at $50 \mathrm{C}$ for 10 minutes, then detect label on probe.

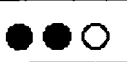

FIGURE 7 Graphic representation of the PCR in situ hybridization protocol. 
hybridization step. A variety of reporter molecules may be used. Digoxygeninand biotin-labeled nucleotides allow for rapid and simple colorimetric detection of the amplified product by the use of the appropriate alkaline phosphatase-labeled conjugate (anti-digoxigenen and streptavidin, respectively). In situ PCR is much quicker and simpler than PCR in situ hybridization. However, in our experience it can only be employed for DNA targets if one is using frozen fixed tissues or cytospins that have not been heated. The power and widespread utility of in situ PCR are much more evident for RNA, where pretreatment overnight in a RNase-free DNase solution allows for target-specific incorporation of the reporter molecule in the cDNA synthesized after the RT step.

\section{RT In Situ PCR}

The two differences of RT in situ PCR with regard to in situ PCR are the overnight digestion in RNase-free DNase done after the protease digestion and the RT step prior to in situ PCR. We have tried DNase digestion from 4 to $15 \mathrm{hr}$ and shown that at least $7 \mathrm{hr}$ are needed to eradicate completely the nonspecific signal after optimal protease digestion. ${ }^{(5)}$ The RT step is done at $42^{\circ} \mathrm{C}$ for $30 \mathrm{~min}$ with a solution made according to the manufacturer's recommendations (RT PCR kit, Perkin-Elmer).

An essential point regarding successful RT in situ PCR is evident from Tables 1 and 2 . Specifically, there is a strong relationship between the protease digestion and formalin fixation times. Adequate protease digestion is defined as an intense signal in $>50 \%$ of the cells and no signal after DNase digestion. It is important to realize that with inadequate protease digestion, one will usually see a signal with DNase digestion that is stronger than for the section not pretreated with DNase. Assuming that the nonspecific signal represents repair of DNA gaps, this DNase enhancement with suboptimal protease may represent enlargement of these putative gaps under conditions where the DNase cannot completely destroy the DNA template. The key concept with regard to RT in situ PCR is that one must perform the positive control (no DNase) and negative control (DNase, no RT) on the same slide as the RT test. A successful run is defined by a strong signal in the positive control and no signal in the negative control (Fig. 8); note that ${ }^{3} \mathrm{H}$ is the reporter molecule. If a signal is seen with the negative control, then the most likely reason is inadequate protease digestion. Thus, the test should be repeated with increasing protease times. Another possible problem is no signal with the positive control and poor morphology. This signifies over digestion of protease and should prompt retesting at lower protease digestion times (Fig. 1).

The final important point about RT in situ PCR concerns the localization of the signal. The signal should localize to different subcellular compartments for the RNA than for the DNA in the positive control, where the signal should be pan-nuclear. This is illustrated in Figure 9. Note the dramatic different patterns evident with various RNAs, suggesting different pathways from the nucleus to the cytoplasm.

\section{APPLICATIONS}

The remainder of this article deals with examples of the in situ detection of PCR-amplified DNA and cDNA to illustrate some of the aforementioned principles.

\section{Detection of the HIV-1 Proviral DNA}

The ability of HIV-1 to synthesize its DNA from its RNA template is very 

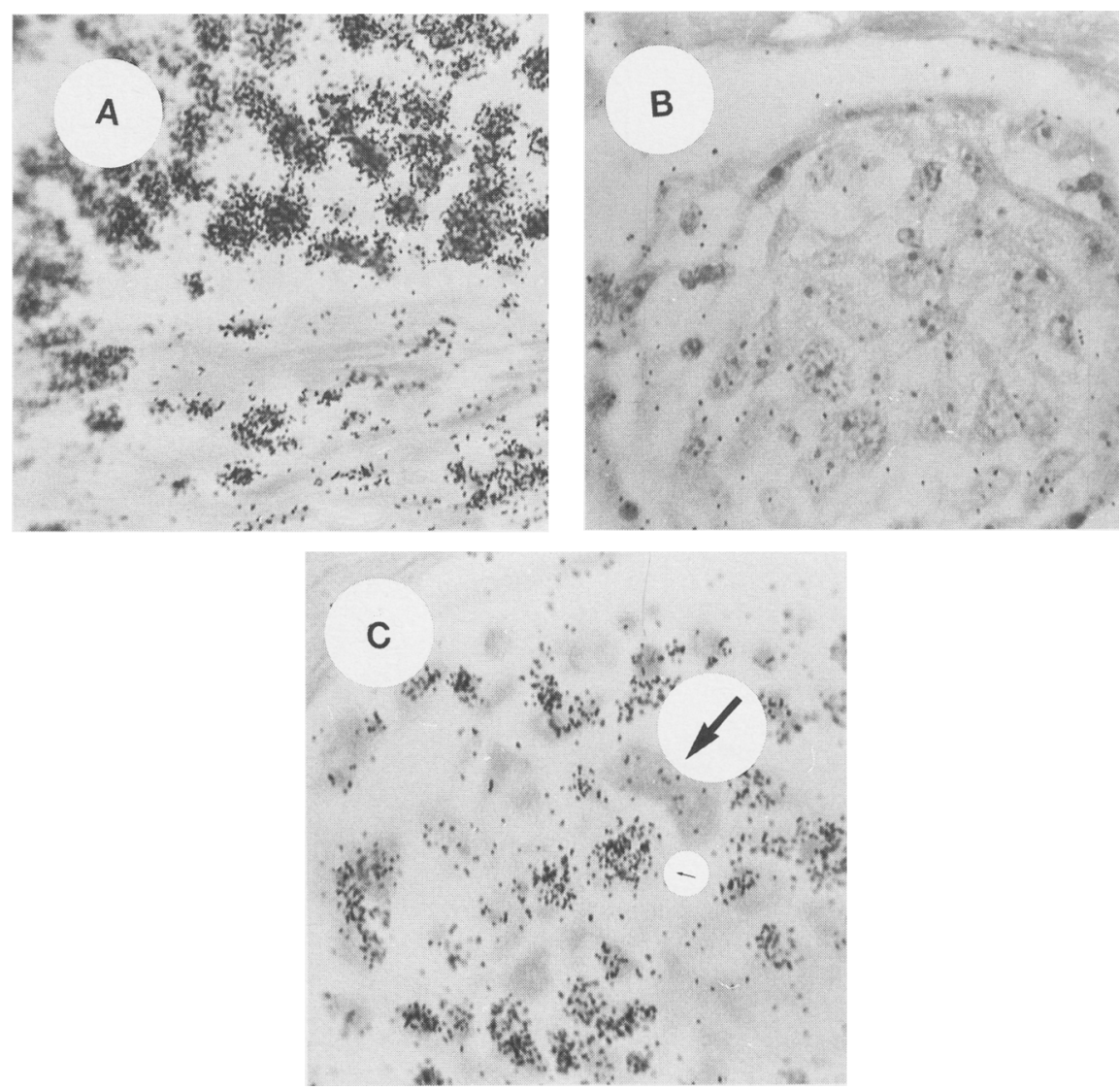

FICURE 8 The importance of the positive and negative controls with RT in situ PCR. This cervical cancer was analyzed for MMP-92 expression using RT in situ PCR and direct incorporation of $\left[{ }^{3} \mathrm{H}\right] \mathrm{dCTP}$. Note the intense nuclear signal with the positive control (no DNase; $A$ ) and the absence of signal with the negative control (DNase, no RT; $B$ ). These reactions were done on the same slide as the test and demonstrated that the protease and DNase digestions were adequate. The RT in situ PCR reaction for MMP-9 was done on the same glass slide. Many cells contained this mRNA; note the cytoplasmic localization of the signal $(C$; small arrow, cytoplasm; large arrow, nucleus).

important to its pathogenesis. The proviral cDNA can integrate into a cell and remain as a latent infection for long periods of time. Importantly, the one to few copies of the viral DNA would not be detectable by standard in situ hybridization. PCR in situ hybridization has provided critical new data about the pathogenesis of HIV-1. These can be summarized as follows:

1. HIV-1 routinely infects (mostly latently) $\sim 30 \%$ of CD4 cells in the lymph nodes in the seropositive, asymptomatic patient. HIV-1 infects $\sim 1-5 \%$ of circulating CD4 cells in this clinical setting. These numbers are much greater than estimated by other methodologies and explain, in part, a mechanism whereby HIV-1 destroys the immune system. ${ }^{(13-17)}$

2. HIV-1 infects the spermatogonia and their progeny in the male genital tract. The target cell for the virus in the female genital tract is the endocervical macrophage. ${ }^{(18,19)}$ This may explain the much greater risk for women compared with men in acquiring AIDS through unprotected sexual relations, as the spermatogonia would not be directly exposed to the virus by this route. Migration of infected endocervical macrophages to the regional lymph nodes could initiate systemic infection in the women.

3. HIV-1 infects (latently) perivascular microglia in the patient with no 

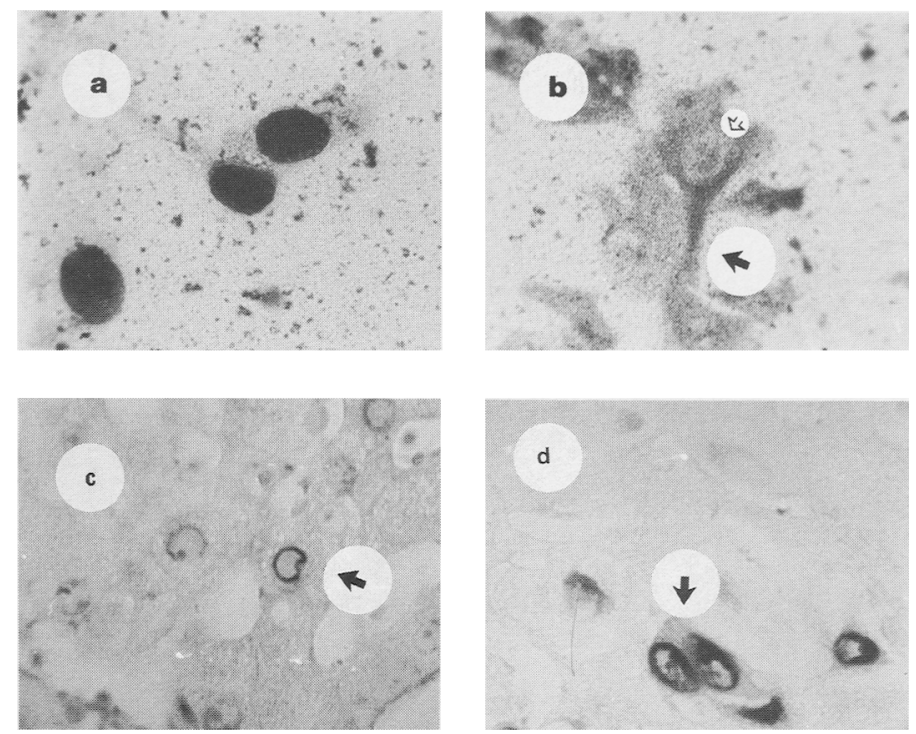

FICURE 9 Different localizations of the signal with RT in situ PCR. The signal with the positive control, representing DNA repair, mispriming, and genomic DNA synthesis, should localize to the nucleus, as is evident with this HT1080 cell line (a). The RNA-based signal should not be pan-nuclear. Variable patterns are seen. For example, a cytoplasmic signal is evident for MMP-92 in this cell line ( $b$; open arrow, negative nucleus, solid arrow-cytoplasmic signal). The signal for PCR-amplified hepatitis $C$ RNA localizes to the junction of the nucleus and cytoplasm in the hepatocyte $(c)$. A perinuclear and cytoplasmic signal is seen for the $\beta$-chain of fibrinogen mRNA in trophoblasts ( $d$; arrow, cytoplasm).

CNS symptoms. AIDS dementia is characterized by a dramatic increase in the number of infected cells, which include astrocytes, microglia, and neurons (Fig. 10). ${ }^{(20)}$ Note how the extent of the infection is grossly underestimated by standard in situ hybridization (Fig 10).

4. AIDS myopathy is associated with the presence of HIV-1 in the macrophages and myocytes in regions of muscle damage. ${ }^{(21)}$

\section{RT In Situ PCR}

RT in situ PCR has been helpful in detecting RNA viruses that, because of their low copy number, are difficult to detect by standard in situ hybridization. An example is hepatitis $C$, which is the most common cause of viral hepatitis in the United States. It has been demonstrated that the viral RNA is difficult to detect weeks after infection in chimpanzees. ${ }^{(22)}$ RT in situ PCR routinely
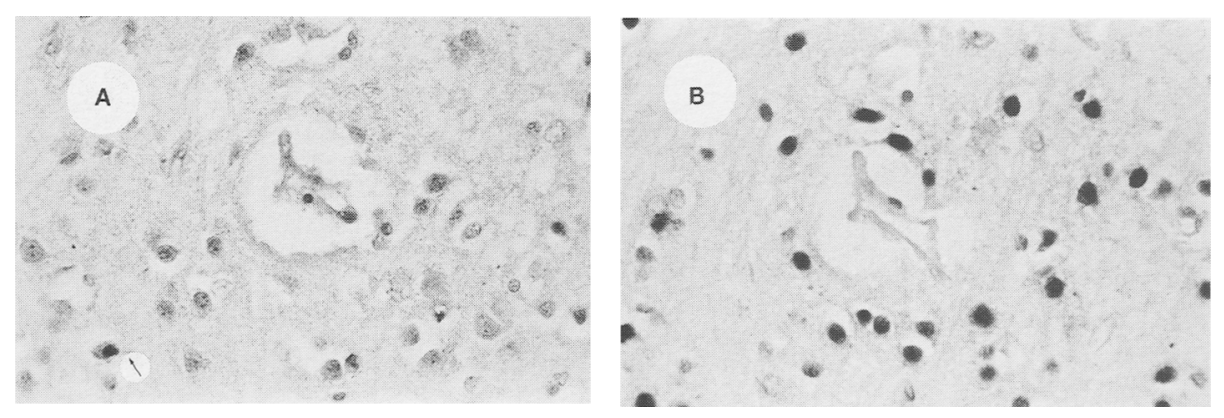

FIGURE 10 Detection of HIV-1 DNA by PCR in situ hybridization in the CNS of a patient with severe AIDS dementia. A few cells had detectable HIV-1 DNA as determined by standard in situ hybridization $(A)$. Note how many more cells had detectable proviral DNA if the in situ hybridization done on the serial section on the same glass slide was preceded by PCR $(B)$. 
detects the virus in liver biopsies and demonstrates that many hepatocytes and occasional Kuppfer cells (the liver macrophage) contain the virus (Fig. $9) .{ }^{(23,24)}$ Note the localization of the signal to the junction of the nucleus and cytoplasm as compared with the intense nuclear signal evident with the section that was not digested in DNase. The reasons for this localization are not clear, although viral antigens present in the cytoplasm can show a localization to below the nuclear membrane. ${ }^{(25)}$ Interestingly, a cytoplamic signal is routinely evident in cell lines infected by hepatitis C.

RT in situ PCR has been very helpful in detecting human mRNAs. Collagenases and their inhibitors (TIMPs) are important elements in the invasion of the surrounding stroma by cancer cells. By using RT in situ PCR, we were able to demonstrate that cancer cells with a poor prognosis produced two collagenases but not the related inhibitors, whereas cancer cells with a good prognosis produced the collagenases and their inhibitors in a ratio of $\sim 1: 1$. An example of the detection of collagenase 92 (MMP-92) is given in Figure 8. Note that the signal for the positive control is stronger than the signal for the amplified cDNA, as it represents three different pathways: mispriming, target specific (genomic), and DNA repair. This illustrates the point that this is a positive control for in situ PCR and not for the target itself. To demonstrate that one is amplifying the target of interest, one can use cell lines known to express the RNA of interest (see Fig. 9).

\section{SUMMARY}

Many groups have now published data based on the in situ detection of PCR-amplified DNA and cDNA. As with standard in situ hybridization or PCR, variables that can affect in situ PCR results include type of fixative and time of fixation, protease digestion, and the composition of the amplifying solution and oligoprobe cocktail. Investigators new to the field of in situ PCR should first try direct incorporation of the reporter molecule into paraffinembedded tissue sections. Although nonspecific DNA synthesis is generated under these conditions, one can develop the confidence of synthesizing DNA inside the nucleus and appreciate the importance of protease digestion time to successful RT in situ PCR. It is an arguable statement that the in situ detection of PCR-amplified DNA and CDNA will have a very strong impact on many diverse fields, such as oncogenesis, embryology, RNA trafficking, and detection of viral diseases, as it already has on our understanding of the pathogenesis of HIV-1 infection.

\section{ACKNOWLEDGMENTS}

I appreciate the help of Mr. John Atwood (Perkin-Elmer) and Mr. S.B. Lewis. This work was supported by grants from the Lewis Foundation, the Center for Biotechnology of the State of New York, and the Perkin-Elmer Corporation (G.J.N.).

\section{REFERENCES}

1. Crum, C.P., G.J. Nuovo, D. Friedman, and S.J. Silverstein. 1988. A comparison of biotin and isotope labeled ribonucleic acid probes for in situ detection of HPV 16 ribonucleic acid in genital precancers. Lab. Invest. 58: 354-359.

2. Nuovo, G.J. 1989. A comparison of slot blot, Southern blot and in situ hybridization analyses for human papillomavirus DNA in genital tract lesions. Obstet. Gynecol. 74: 673-677.

3. Nuovo, G.J. and R.M. Richart. 1989. A comparison of different methodologies (biotin based and $35 S$ based) for the detection of human papillomavirus DNA. Lab. Invest. 61: 471-476.

4. Nuovo, G.J. 1993. Cytopathology of the cervix and vagina: An integrated approach. Williams and Wilkins, Baltimore, MD.

5. Nuovo, G.J. 1994. PCR in situ hybridization: Protocols and applications, 2nd ed. Raven Press, New York.

6. Erlich, H.A., D. Gelfand, and J.J. Sninsky. 1991. Recent advances in the polymerase chain 
reaction. Science 252: 1643-1650.

7. Chou, Q., M. Russell, D.E. Birch, J. Raymond, and W. Bloch. 1992. Prevention of pre-PCR mis-priming and primer dimerization improves low copy number amplifications. Nucleic Acids Res. 20: 1717-1723.

8. Nuovo, G.J., F. Gallery, P. MacConnell, J. Becker, and W. Bloch. 1911. An improved technique for the detection of DNA by in situ hybridization after PCR amplification. Am. J. Pathol. 139: 1239-1244.

9. Greer, C.E., S.L. Peterson, N.B. Kiviat, and M.M. Manos. 1991. PCR amplification from paraffin-embedded tissues: Effects of fixative and fixative times. Am. J. Clin. Pathol. 95: 117-124.

10. Nuovo, G.J. and S.J. Silverstein. 1988. Comparison of formalin, buffered formalin, and Bouin's fixation on the detection of human papillomavirus DNA from genital lesions. Lab. Invest. 59: 720-724.

11. Nuovo, G.J., F. Gallery, R. Hom, P. MacConnell, and W. Bloch. 1993. Importance of different variables for optimizing in situ detection of PCR-amplified DNA. PCR Methods Applic. 2: 305312.

12. Nuovo, G.J., F. Gallery, and P. MacConnell. 1994. Analysis of nonspecific DNA synthesis during in situ PCR. PCR Methods Applic. 4: 342-349.

13. Nuovo, G.J., J. Becker, M. Margiotta, M. Burke, J. Fuhrer, and R. Steigbigel. 1994. In situ detection of PCR-amplified HIV-1 nucleic acids in lymph nodes and peripheral blood in asymptomatic infection and advanced stage AIDS. J. Acquired Immun. Def. 7: 916-923.

14. Patterson, B.K., M. Till, P. Otto, et al. 1993. Detection of HIV-1 DNA and messanger RNA in individual cells by PCR-driven in situ hybridization and flow cytometry. Science 260: 976979.

15. Embretson, J., M. Zupancic, J.L. Ribas, et al. 1993. Massive covert infection of helper T lymphocytes and macrophages by HIV during the incubation period of AIDS. Nature 362: 359-362.

16. Bagasra, O., S.P. Hauptman, H.W. Lischer, M. Sachs, and R.J. Pomerantz. 1992. Detection of human immunodeficiency virus type 1 provirus in mononuclear cells by in situ polymerase chain reaction. N. Engl. J. Med. 326: 1385-1391.

17. Nuovo, G.J., M. Margiotta, P. MacConnell, and J. Becker. 1993. Rapid in situ detection of PCR-amplified HIV-1 DNA. Diagn. Mol. Pathol. 1: 98-102.

18. Nuovo, G.J., J. Becker, A. Simsir, M. Margiotta, and M. Shevchuck. 1994. In situ localization of PCR-amplified HIV-1 nucleic acids in the male genital tract. Am. J. Pathol. 144: 1142-1148.

19. Nuovo, G.J., A. Forde, P. MacConnell, and R. Fahrenwald. 1993. In situ detection of PCRamplified HIV-1 nucleic acids and tumor necrosis factor cDNA in cervical tissues. Am. J. Pathol. 143: 40-48.

20. Nuovo, G.J., F. Gallery, P. MacConnell, an A. Braun. 1994. In situ detection of PCR-amplified HIV-1 nucleic acids and tumor necrosis factor RNA in the central nervous system. Am. J. Pathol. 144: 659-666.

21. Seidman, R., N. Peress, and G.J. Nuovo. 1994. In situ detection of PCR-amplified HIV-1 nucleic acids in skeletal muscle in patients with myopathy. Mod. Pathol. 7: 369-375.

22. Negron, F., D. Pacchioni, Y. Shimizu, R.H. Miller, G. Bussolati, R.H. Purcell, and F. Bonino. 1992. Detection of intrahepatic replication of hepatitis C virus RNA by in situ hybridization and comparison histopathology. Proc. Natl. Acad. Sci. 89: 2247-22271.

23. Lidonnici, K., B. Lane, and G.J. Nuovo. 1995. A comparison of serologic analysis and in situ localization of PCR-amplified cDNA for the diagnosis of hepatitis C infection. Diagn. Mol. Pathol. (in press).

24. Nuovo, G.J., K. Lidonocci, P. MacConnell, and B. Lane. 1993. Intracellular localization of PCR-amplified hepatitis C cDNA. Am. J. Pathol. 17: 683-690.

25. Nuovo, G.J. (unpubl.). 


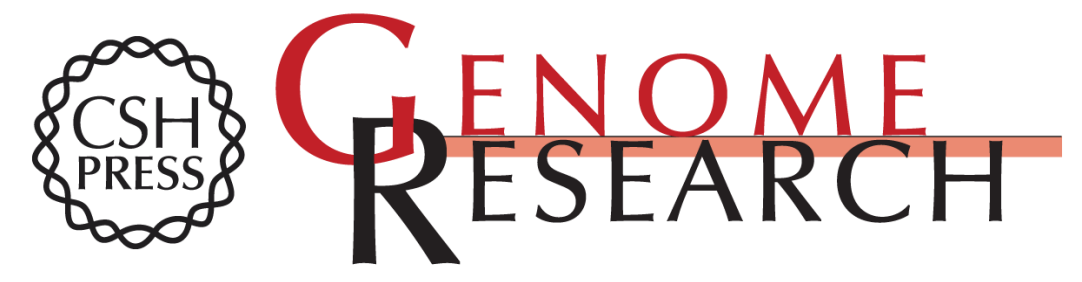

\section{In situ PCR: protocols and applications.}

G J Nuovo

Genome Res. 1995 4: S151-S167

References This article cites 21 articles, 3 of which can be accessed free at: http://genome.cshlp.org/content/4/4/S151.full.html\#ref-list-1

\section{License}

Email Alerting Receive free email alerts when new articles cite this article - sign up in the box at the Service top right corner of the article or click here.

\section{Affordable, Accurate Sequencing.}

To subscribe to Genome Research go to: https://genome.cshlp.org/subscriptions 